\title{
Chronic prescribed burning alters nutrient deposition and sediment stoichiometry in a lake ecosystem
}

\author{
Matthew N. Waters, Alexander P. Metz, Joseph M. Smoak, \\ Hunter Turner
}

Received: 26 March 2018/Revised: 6 August 2018/Accepted: 20 August 2018/Published online: 1 September 2018

\begin{abstract}
Prescribed fire is a common management practice for forests and other terrestrial environments. Following a prescribed burn, ash erodes into aquatic environments potentially altering terrestrial-aquatic connectivity and water quality. In this study, we collected a sediment core from Ocean Pond, FL, USA, a lake that has received fire ash from decades of prescribed burning events. Paleolimnological measurements of macrocharcoal, nutrients, stable isotopes $\left(\delta^{13} \mathrm{C}, \delta^{15} \mathrm{~N}\right)$, and photosynthetic pigments were used to reconstruct fire regimes, material inputs, and lake primary producer responses for periods of prescribed burns and other lake periods throughout the last 6000 years. Results show that the period of repeated modern-prescribed fires coincided with decreased $\mathrm{C}$ and $\mathrm{N}$ depositions in the lake, while $\mathrm{P}$ deposition increased causing alterations to nutrient storage and stoichiometry. However, photosynthetic pigments indicated low primary producer abundance during the prescribed fire period. These changes in nutrient dynamics could provide new insights into biogeochemical pathways in land-water connected systems where burning has not been considered.
\end{abstract}

Keywords Carbon · Nutrients · Paleolimnology ·

Prescribed fire $\cdot$ Sediments · Stoichiometry

\section{INTRODUCTION}

Prescribed fire is a common management tool in forestry where fires are used to simulate natural fire events to prevent wildfire occurrences and support biogeochemical processes in forest soils (Ryan et al. 2013). Controlled burns aid in fuel reduction, land clearance, and biogeochemical cycling by reducing understory capable of promoting wildfires and returning nutrients to forest soils through deposited pyro-materials (Vose et al. 1999). In the pine-dominant forests of the southeastern USA, fire can be the primary environmental and management force maintaining the coastal plain woodlands. In 2016 alone, the US states of Florida, Georgia, and Alabama burned $7716 \mathrm{~km}^{2}$ using controlled burn methods (National Interagency Fire Center, www.nifc.gov). While application of prescribed fire is a well-established management tool for forest ecosystems and other terrestrial landscapes, the materials produced and exported during repeated burn events to adjacent ecosystems appear to be less understood.

Following a burn event, materials can erode into nearby aquatic environments causing episodic changes to biogeochemical cycles and water quality (Moody et al. 2013). These alterations in erosional dynamics change with landscape features and fire intensity (Haliuc et al. 2016). Inputs of specific elements from burned areas can increase $(\mathrm{P}, \mathrm{Ca}, \mathrm{Mg}, \mathrm{K})$ or decrease $(\mathrm{C}, \mathrm{N})$ based on volatility during burning and cycling in the soil environment (Kloss et al. 2012; Leys et al. 2016). For example, C and N, which have common gaseous species to their biogeochemistry, can decrease in amount and transport following a fire due to evasion as gases (Dunnette et al. 2014). Conversely, phosphorus lacks a gaseous biogeochemical component and has been shown to increase inputs into aquatic environments when burned areas are compared to unburned areas (Johnson et al. 2014; Leys et al. 2016). In addition to nutrient concentrations, burn events can increase stable isotopic ratios of eroded nutrients by the lighter isotopes of $\mathrm{C}$ and $\mathrm{N}\left({ }^{12} \mathrm{C},{ }^{14} \mathrm{~N}\right)$ readily volatilize, leaving the heavier isotope to cycle through the terrestrial and aquatic ecosystems. Dunnette et al. (2014) showed alterations to isotopic signatures in lake sediments collected from Colorado, USA with fire severity playing a driving role in $\mathrm{C}$ and $\mathrm{N}$ dynamics. While research has 
demonstrated that fires alter nutrient inputs to aquatic systems, fire also impacts soil properties. The remaining ash from prescribed burns can increase $\mathrm{pH}$ and $\mathrm{Ca}$ availability in the terrestrial landscape (Battle and Golladay 2003), which is capable of producing an alkaline solution (Bodi et al. 2014). Wanthongchai et al. (2008) measured soils in a prescribe burned area in Thailand and showed erosional losses of $\mathrm{P}, \mathrm{Ca}$, and $\mathrm{K}$ to nearby stream environments.

The increase in $\mathrm{P}$ and subsequent decreases in $\mathrm{C}$ and $\mathrm{N}$ can alter aquatic nutrient dynamics and stoichiometry, thus impacting aquatic primary producers. Decreases in N/P ratios can favor cyanobacteria dominance since many species of cyanobacteria are capable of fixing atmospheric nitrogen (Paerl et al. 2011). Also, increased Ca concentrations in runoff water in addition to $\mathrm{pH}$ increases could bind phosphorus into apatite-like particles and change phosphorus biogeochemistry of streams and lakes near burned areas (Stephens et al. 2004). Turbidity can also increase due to sediment erosion from recently burned patches, thus limiting light and decreasing productivity (Parlak et al. 2015). While the link between prescribed fire and water quality is becoming established, a large body of research has focused on episodic and acute impacts from large burning events. Very little research has been carried out to investigate the long-term effects on biogeochemistry and biological organisms in aquatic ecosystems near prescribed burn areas that are burned repeatedly over many decades. One method that could be used to answer these types of research questions on chronic fire impacts is to apply paleolimnological techniques to sediment cores collected from lakes in prescribed-burned areas.

Paleolimnology is the study of lake histories inferred from sediment cores. Materials and organisms enter the lake and are delivered to the sediments forming a historic record of past environments within and around the lake system (Smol 2008). Previous research on historic forest fires has shown that charcoal deposition accurately records local fire histories when larger pieces of charcoal (macrocharcoal) are counted (Mohr et al. 2000). Whitlock and Larsen (2001) showed that charcoal fragments $>125 \mu \mathrm{m}$ represented local fires, while smaller pieces could enter lakes from far-off areas providing a regional signal. In addition, many of the water-quality parameters that are altered by prescribed burns can also be measured using paleolimnological techniques. Influxes of nutrients $(\mathrm{C}, \mathrm{N}, \mathrm{P})$ and other elements $(\mathrm{Fe}, \mathrm{S})$ have been analyzed in lake sediments and used to trace nutrient inputs from terrestrial landscapes in watersheds (Schelske et al. 2005; Waters et al. 2010). Stable isotopes of carbon and nitrogen can be used to determine the origins of materials entering lakes and separate terrestrial influences such as tree material from direct human inputs like waste or agricultural runoff (Brenner et al. 1999). Another aspect of water quality that paleolimnological tools can uncover is the response of primary producer communities to waterquality parameters. Aquatic plants, algae, and cyanobacteria have been shown to be sensitive responders to waterquality changes (Smol 2008). C/N ratios can detect the differences in structural carbon between aquatic plant material and algal material (Meyers and Teranes 2001) while the measurement of photosynthetic pigments can be used to show changes in the algal/cyanobacteria community over time (Leavitt and Hodgson 2001; Waters et al. 2015).

Multiple investigations have utilized paleolimnological techniques to link fire occurrences with biogeochemical alterations to forest soils and materials eroded into adjacent aquatic ecosystems. Leys et al. (2016) compared elemental deposition in lake sediments to a reconstructed wildfire record and noted that $\mathrm{Ti}, \mathrm{Ca}, \mathrm{K}, \mathrm{Al}$, and $\mathrm{P}$ increased following burning events. Hudiburg et al. (2017) used a 4500 year sediment record to link fire-regime variability with sedimentary $\mathrm{C}$ dynamics. Using an 800 year sediment record of forest succession, Smithwick et al. (2005) showed that fire was a primary driver of $\mathrm{N}$ dynamics in boreal and northern temperate forests. While the link between fire and biogeochemical dynamics has been established for millennial timescales, very little research utilizing sediment records have focused on the impacts of prescribed burning management practices on erosional dynamics and water quality over decadal timescales. Given that biogeochemical reset periods following burning events have been suggested as a decadal phenomenon (Leys et al. 2016), the repeated burning for many prescribed burning management programs could produce nonnatural results for erosional inputs of nutrients into aquatic ecosystems.

Here paleolimnological tools were applied to a $1.4 \mathrm{~m}$ sediment core collected from Ocean Pond, FL, USA to investigate the impacts of prescribed fire and other fire events on eroded nutrients and aquatic primary producers from the mid-Holocene ( $\sim 6000$ years before present) to present. Ocean Pond is located inside the Osceola National Forest where prescribed burning (Rx-fire) has been occurring on annual to bi-annual rotations since the 1930s. The primary objectives of this study were to (1) determine the impacts of chronic prescribed fire (past $\sim 100$ years) on nutrient deposition and stoichiometry of lake sediments; (2) investigate if the changes in sediment characteristics corresponded to changes in lake primary producer abundance and community structure; and (3) compare nutrient depositions and aquatic ecological changes in the modern Rx-fire period with other periods of the lake's history including pre-European settlement and historic fire periods to see if prescribed fire simulates "natural" fire biogeochemical regimes. 


\section{MATERIALS AND METHODS}

\section{Study site}

Ocean Pond, FL is a natural lake located in the Osceola National Forest in NE Florida, USA. The lake has a surface area of $7.12 \mathrm{~km}^{2}$ and is shallow (average depth $\sim 3 \mathrm{~m}$ ) (Fig. 1). The United States Forest Service maintains the forest and the lake, which includes a camping site and the site of the Civil War Battle of Olustee (www.fs.usda.gov/ main/osceola/home). The Osceola National Forest has been described as flat, uniform pinelands unsuitable for agriculture (Dusenbury 1979). Beginning in 1930, the Osceola National Forest was the location of research investigating the use of prescribed fire as a management tool to prevent wildfire occurrences (Dusenbury 1979). These investigations were central in establishing the policy of the National Forest Service, USA, to apply prescribed burning as a primary management practice (Dusenbury 1979). By 1944, the Osceola National Forest adopted a prescribed burning strategy of $20 \%$ of the forest annually, which has continued to the present day (Dusenbury 1979). The forest consists of a pine-dominated community with smaller areas of swamps and wetlands (www.fs.usda.gov/osceola). A lake survey of Ocean Pond conducted in 1987 noted that the lake was acidic ( $\mathrm{pH} 5.0$ ), low in conductivity $(35 \mu \mathrm{S} / \mathrm{cm}$ ), with moderate amount of nutrients when compared to hypereutrophic and oligotrophic systems in Florida, USA (Brenner and Binford 1988).

\section{Core collection and description}

A 144-cm sediment core was collected in 2016 from Ocean Pond, FL (N30 $13^{\prime} 33.6^{\prime \prime}$, W82 $\left.26^{\prime} 38.3^{\prime \prime}\right)$ using a piston corer designed to retrieve undisturbed surface sediments and deeper sediment sections in 1-m increments. Core location was determined by a soft-sediment survey of 15 sites throughout the open-water areas of the lake to determine areas of sediment deposition. Navigation to the core site was achieved using a hand-held GPS unit. The core was immediately sectioned at $2-\mathrm{cm}$ intervals to $60 \mathrm{~cm}$ with $4-\mathrm{cm}$ sections below $60 \mathrm{~cm}$. Samples were stored on ice and returned to the laboratory. A wet aliquot was removed from each section for macrocharcoal and bulk density analysis, and the remaining samples were frozen, freeze-dried, and ground with a mortar and pestle prior to analysis.

\section{Sediment chronology}

Sediment chronology was based on the excess ${ }^{210} \mathrm{~Pb}$ using the CRS model (Appleby and Oldfield 1983) and three calibrated AMS ${ }^{14} \mathrm{C}$ samples measured on charcoal fragments collected from the core (Table 1). ${ }^{210} \mathrm{~Pb}$ was measured on dried, ground sediment samples using a lowbackground germanium well detector and was used to provide core section dates for the past 110 years. Sediments were sealed with epoxy in test tubes for a minimum of 20 days to allow for secular equilibrium. AMS ${ }^{14} \mathrm{C}$ samples were analyzed at the University of Georgia Center for Applied Isotope Studies and calibrated using CALIB 7.1 (Stuiver et al. 2018). Sample materials measured for ${ }^{14} \mathrm{C}$ were charcoal fragments removed from core depths of 92, 96 and $116 \mathrm{~cm}$ and were used to minimize reservoir effect on obtained dates. These two dating techniques were combined with bulk density measurements to determine sedimentation rates and ages for each core section.

\section{Charcoal}

Charcoal was determined as "macro-charcoal," following the methods of Whitlock and Larsen (2001). One-two $\mathrm{cm}^{3}$ of wet sediment was weighed into a centrifuge tube, and $10 \mathrm{ml}$ of $3 \% \mathrm{KOH}$ solution was added. The mixture was vortexed and allowed to remain overnight. The tubes were centrifuged, and the supernatant was discarded. The pellet was resuspended in 5\% hydrogen peroxide and allowed to remain overnight. This mixture was wet-sieved through a $125-\mu \mathrm{m}$ mesh sieve. The fractions were dried and moved to a gridded petri dish. Charcoal pieces were counted under a dissecting light microscope at 20x magnification and reported as pieces of charcoal $\mathrm{cm}^{-2}$ year ${ }^{-1}$ based on the dating model for the entire core.

\section{Gravimetric analysis}

For bulk density measurements, a known volume of wet sediment was dried in a drying oven at $65^{\circ} \mathrm{C}$. Bulk density is expressed as $\mathrm{g} \mathrm{dry} \mathrm{cm}^{-3}$ wet. Organic matter, as weight loss on ignition (LOI), was measured as a percentage of dry mass, following burning at $550^{\circ} \mathrm{C}$ in a muffle furnace for $2 \mathrm{~h}$.

\section{Nutrients and stable isotopes}

Total organic carbon (TOC) and total nitrogen (TN) were measured on organic sediment fractions using a Costech $\mathrm{CN}$ analyzer with an attached autosampler. Prior to analysis, TOC and TN samples were acidified for $12 \mathrm{~h}$ in $\mathrm{HCl}$ vapors to remove inorganic carbon. Stable isotopes $\left(\delta^{13} \mathrm{C}\right.$, $\delta^{15} \mathrm{~N}$ ) were measured on bulk sediment samples using an isotopic mass spectrometry system coupled to the $\mathrm{CN}$ analyzer and compared to reference standards of Pee Dee Belemnite and air, respectively, at the University of Georgia Center for Isotope Studies. Phosphorus was measured on dried sediments using an ARL 3560AES ICP 


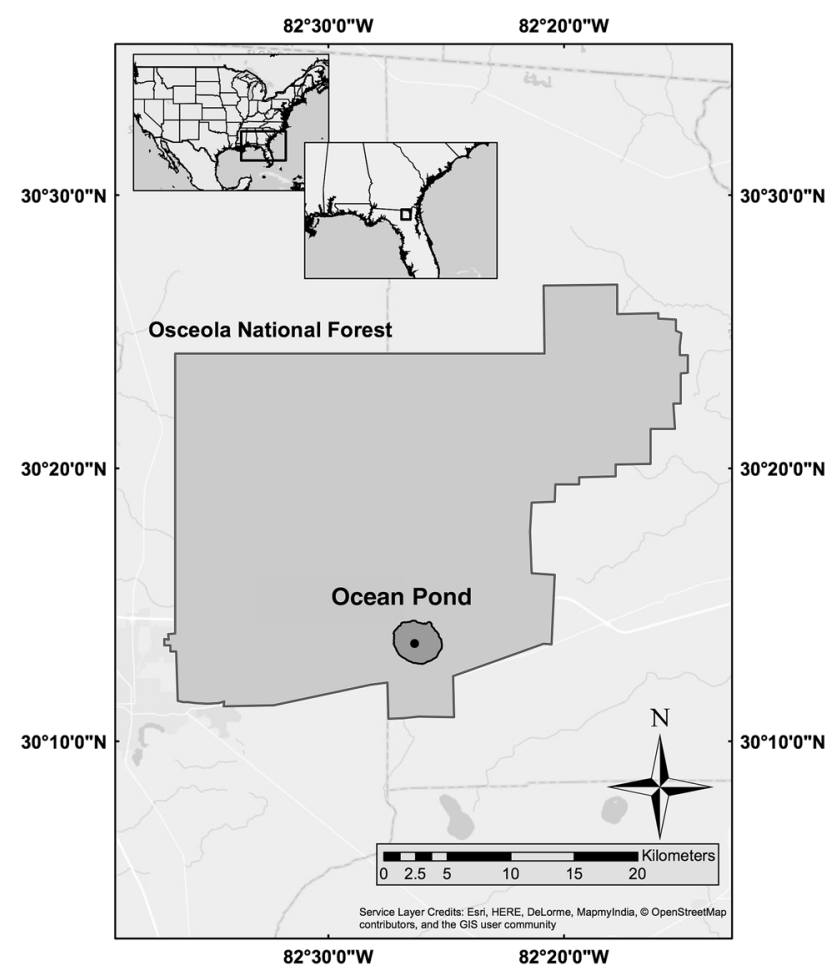

Fig. 1 Map of Ocean Pond, FL showing the core site (filled circle). Inset maps show the lower 48 states of the USA and Florida with a square marking the location of Ocean Pond

analyzer following nitric acid digestion for $90 \mathrm{~min}$ in a heated block (EPA 6010B).

\section{Photosynthetic pigments}

Photosynthetic pigments (chlorophylls and carotenoids) were measured using HPLC (High Performance Liquid Chromatography), following the methods of Leavitt and Hodgson (2001) and Waters et al. (2015). Dried sediment samples were extracted with a solvent mixture of acetone, methanol, and water mixed in a ratio of 80:15:5, which contained an internal standard (Sudan II; Sigma Chemical Corp., St. Louis, MO). Extraction was done for 16-20 h in a $-20^{\circ} \mathrm{C}$ freezer. Following extraction, samples were centrifuged and filtered through a $0.22-\mu \mathrm{m}$ syringe filter to remove particulate matter. Samples were placed in an autosampler tray where they were mixed with an ion-pairing agent $(0.75 \mathrm{~g}$ tetrabutyl ammonium acetate and $7.7 \mathrm{~g}$ ammonium acetate in $100 \mathrm{ml}$ HPLC-grade water), just prior to injection in a 3:1 ratio (sample:ion pairing agent). A $100-\mu l$ aliquot of this mixture was injected into a Shimadzu HPLC system, following the mobile phase and time sequence of Leavitt and Hodgson (2001). Chlorophylls and carotenoids were separated by passing through a Phenomenex Luna C18 column. Carotenoids were measured using a photodiode array detector, and chlorophylls and chlorophylldegradation products were measured using a fluorescence detector. Pigments were identified using retention times and pigment-specific spectra of known standards (DHI Lab Products, Denmark). Pigment concentrations are expressed as $\mathrm{nmol} \mathrm{g}^{-1}$ organic matter and were calculated by comparing peak areas against standards of known concentration. Photosynthetic pigments were measured within a week after freeze-drying to minimize post-drying degradation.

\section{Sediment zonation}

Sediment clusters based on nutrient $(\mathrm{C}, \mathrm{N}, \mathrm{P})$ and charcoal deposition were objectively determined using $\mathrm{K}$-means cluster analysis (SAS JMP, 2016). K-means cluster analysis uses a specified number of cluster seed points and repetitively groups data to minimize standard deviations of means for each group. In addition, a principal component analysis was performed on the variables, macrocharcoal, $\mathrm{C}$, $\mathrm{N}, \mathrm{P}$, and Beta-Carotene, to determine the ordination of stratigraphic sections with different variables.

\section{RESULTS}

The Ocean Pond sediment core was dark brown organic matter throughout the core with the exception of a sand layer from 132 to $116 \mathrm{~cm}$. A robust chronological framework was developed by combining the excess ${ }^{210} \mathrm{~Pb}$ profile and the three calibrated AMS ${ }^{14} \mathrm{C}$ samples on charcoal (Table 1). Excess ${ }^{210} \mathrm{~Pb}$ reached supported levels at $22 \mathrm{~cm}$ and the CRS model was used to calculate dates and sedimentation rates for the top $20 \mathrm{~cm}$ of the core (Fig. 2). Aside from the top sample of the core, excess ${ }^{210} \mathrm{~Pb}$ increased up core from $22 \mathrm{~cm}$ to $4 \mathrm{~cm}$. Sedimentation rates calculated from the ${ }^{210} \mathrm{~Pb}$ record averaged $15.4 \pm 5.2 \mathrm{mg} \mathrm{cm}^{-2}$ year ${ }^{-1}$. The bottom age of the ${ }^{210} \mathrm{~Pb}$ record and the three AMS ${ }^{14} \mathrm{C}$ dates obtained from macrocharcoal fragments were used to determine sedimentation rates and ages for the remaining core sections. In between each measured age, the total summarized sediment mass was divided by the number of years represented in the core section. This sediment per year was multiplied by bulk density of each core section to determine the age and sedimentation rate for the entire core. Combining these two dating techniques showed that the sediment core represented the past $\sim$ $6000 \mathrm{YBP}$ and the core sections below the ${ }^{210} \mathrm{~Pb}$ record averaged sedimentation rates of $2.25 \pm 2.1 \mathrm{mg} \mathrm{cm}^{-2}$ year $^{-1}$.

Three clusters of sediments were identified based on their nutrient and macrocharcoal contents (Fig. 3). Cluster $1(n=9)$ was composed of the top $18 \mathrm{~cm}$ of the core and 
Table 1 AMS ${ }^{14} \mathrm{C}$ samples from the Ocean Pond, FL sediment core

\begin{tabular}{llllll}
\hline $\begin{array}{l}\text { Lab } \\
\text { sample } \\
\text { ID }\end{array}$ & $\begin{array}{l}\text { Sample } \\
\text { material }\end{array}$ & $\begin{array}{l}\text { Core } \\
\text { depth } \\
(\mathrm{cm})\end{array}$ & $\begin{array}{l}\delta^{13} \mathrm{C} \\
(\%)\end{array}$ & $\begin{array}{l}{ }^{14} \mathrm{C} \text { age } \\
(\mathrm{BP})\end{array}$ & $\begin{array}{l}\text { Calibrated age } \\
(95 \% \mathrm{CI})\end{array}$ \\
\hline 25218 & Charcoal & 92 & -25.1 & $5380 \pm 30$ & $4278 \pm 54$ \\
25219 & Charcoal & 96 & -27.9 & $5660 \pm 30$ & $4499 \pm 54$ \\
25220 & Charcoal & 116 & -23.5 & $7500 \pm 30$ & $6390 \pm 48$
\end{tabular}

$\overline{\delta^{13} \mathrm{C} \text { values are calculated against the reference standard, Pee Dee }}$ Belemnite. Age dates were calculated using the Calib 7.0 program and reflect years before 1950 AD (Stuiver et al. 2018)

corresponded to the modern $\mathrm{Rx}$-fire period based on the excess- ${ }^{210} \mathrm{~Pb}$ dates. This cluster also contained moderate amounts of $\mathrm{C}$ and $\mathrm{N}$ and over $200 \%$ more $\mathrm{P}$ than the other clusters. To demonstrate changes in sedimentary nutrient stoichiometry, N/P was calculated from the cluster breaks but not included in the cluster analysis (Fig. 3). Cluster 2 $(n=8)$ contained moderate amounts of macrocharcoal and the lowest concentrations of all nutrients measured. Based on visual inspection of the core, Cluster 2 is associated with levels in the core with higher sand deposition as shown in LOI and bulk density measurements (Fig. 4). Cluster $3(n=34)$ appears to be associated with periods in the lake's history that precedes modern human impacts and $\mathrm{Rx}$-fire where deposition was more associated with organic matter than sand.

Macrocharcoal fragments deposited in the sediments of Ocean Pond recorded the period of prescribed fires as well as other fire events (Fig. 4). Pre-modern Rx-fire events were inferred from spikes in macrocharcoal deposition at depths of 144 to $136 \mathrm{~cm}, 116$ to $112 \mathrm{~cm}$, and $96 \mathrm{~cm}$ corresponding to ages of $>6400$ Years-Before-Present (YPB), 6400 YBP, and 4500 YBP, respectively. Low charcoal deposition occurred from 92 to $20 \mathrm{~cm}$ with large increases in charcoal deposition and the highest values for the core in the upper $20 \mathrm{~cm}$. LOI, total organic carbon (TOC), and total nitrogen (TN) displayed similar stratigraphic trends throughout the core (Fig. 4). Values were variable from the bottom of the core to $92 \mathrm{~cm}$ with the lowest values occurring in sand layers (Cluster 2, $132-116 \mathrm{~cm})$. Values were the highest from 92 to $20 \mathrm{~cm}$ for all three measurements decreasing in the upper $20 \mathrm{~cm}$ of the core. From the bottom of the core to $48 \mathrm{~cm}$, total phosphorus (TP) concentrations were low with a gradual increase to $20 \mathrm{~cm}$. TP concentrations increased and maintained the highest levels in the core in the upper $20 \mathrm{~cm}$ corresponding to Cluster 1 and the modern prescribed burning period (Fig. 4). TOC/TN oscillated between 6 and 25 from the bottom of the core to $82 \mathrm{~cm}$ indicating depositions of both terrestrial and aquatic organic material. From $82 \mathrm{~cm}$ to the top of the core, TOC/TN values remained between 25 and 30 (Fig. 4), indicating a dominance of terrestrial material. $\delta^{13} \mathrm{C}$ values were between -25 and $-27 \%$ for the entire core with the exception of $116 \mathrm{~cm}$ where values increased to - 24\%o (Fig. 4).

Carotenoid concentrations of beta carotene (total abundance), diatoxanthin (diatoms), canthaxanthin (cyanobacteria), and lutein + zeaxanthin (chlorophytes + cyanobacteria) peaked at depths similar to the historic fire periods (146 and $94 \mathrm{~cm}$ ) (Fig. 5). All five pigments showed small increases in the top of the core. Alloxanthin followed a similar stratigraphy as the other carotenoids with the exception that the high concentrations at $94 \mathrm{~cm}$ continued up-core to $42 \mathrm{~cm}$. Chlorophyll-a maintained low concentrations from the bottom of the core to around $24 \mathrm{~cm}$ with small increases at 146, 116, 90, and $86 \mathrm{~cm}$ (Fig. 5). Concentrations for chlorophyll-a increased in the upper portion of the core.

Principal component analysis separated core sections based on the variables chosen that corresponded with the k-means clusters (Fig. 6). Principal components 1 (PC1) and 2 (PC2) accounted for $54.8 \%$ and $26.1 \%$ of the dataset variance, respectively. In addition, variables macrocharcoal (Char) and phosphorus $(\mathrm{P})$ ordinated with the Rx-fire core sections, while carbon and nitrogen ordinated with the low fire periods (Fig. 6).

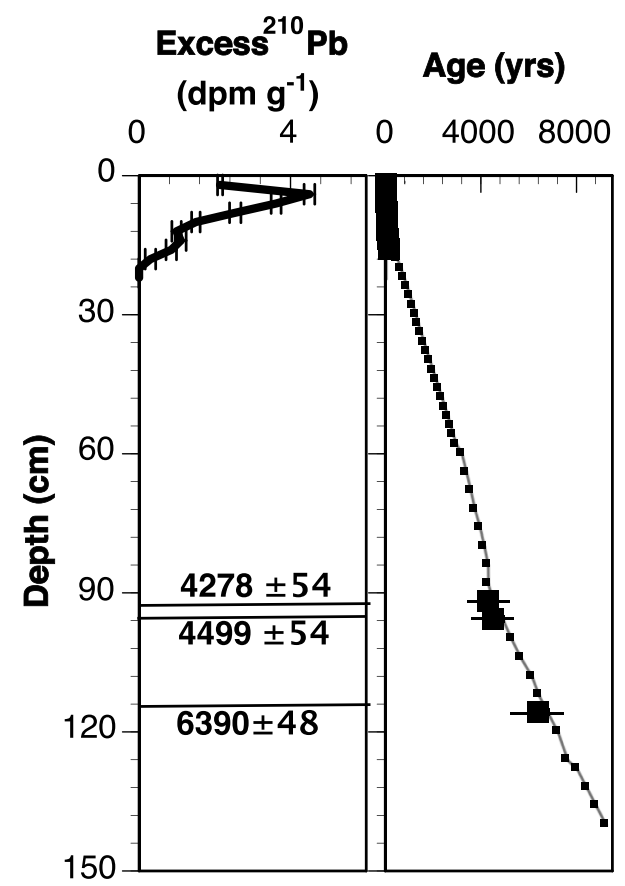

Fig. 2 Excess ${ }^{210} \mathrm{~Pb}$ (left panel) and Age (right panel) versus depth for the Ocean Pond, FL sediment core. Lines on left panel show the three calibrated $\mathrm{AMS}^{14} \mathrm{C}$ dates (Stuiver et al. 2018). For the right panel, large symbols represent ages formulated from ${ }^{210} \mathrm{~Pb}$ or $\mathrm{AMD}^{14} \mathrm{C}$ measurements with error bars of one standard deviation. Smaller symbols are calculated dates from the dating model 

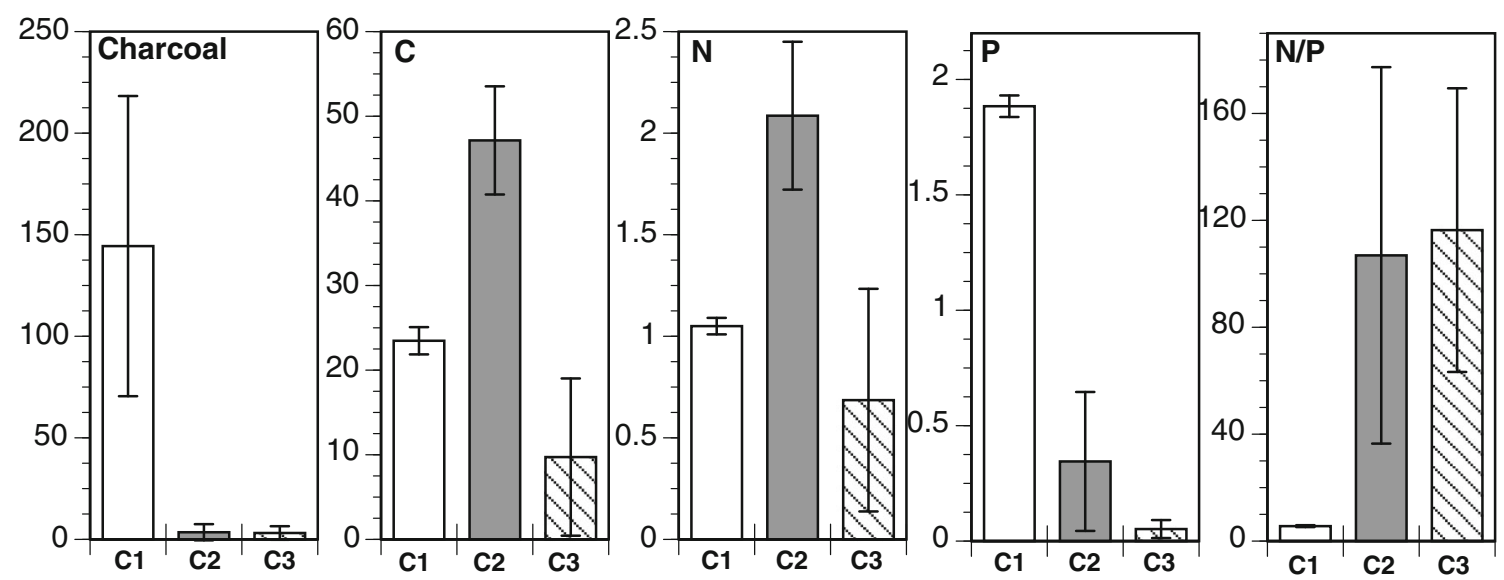

Fig. 3 Cluster means determined from K-means cluster analysis (3 clusters) of macrocharcoal (\# $\mathrm{cm}^{-2} \mathrm{year}^{-1}, \mathrm{C}(\%), \mathrm{N}(\%)$, and $\mathrm{P}\left(\mathrm{mg} \mathrm{g} \mathrm{g}^{-1}\right)$. N/P molar ratio means were determined from the cluster breaks. Error bars are one standard deviation above and below the mean. Cluster 1 is inferred as the modern Rx-fire period, and cluster 2 is inferred as historic periods of sand deposition. Cluster 3 represents the remaining sediment sections including the low fire periods

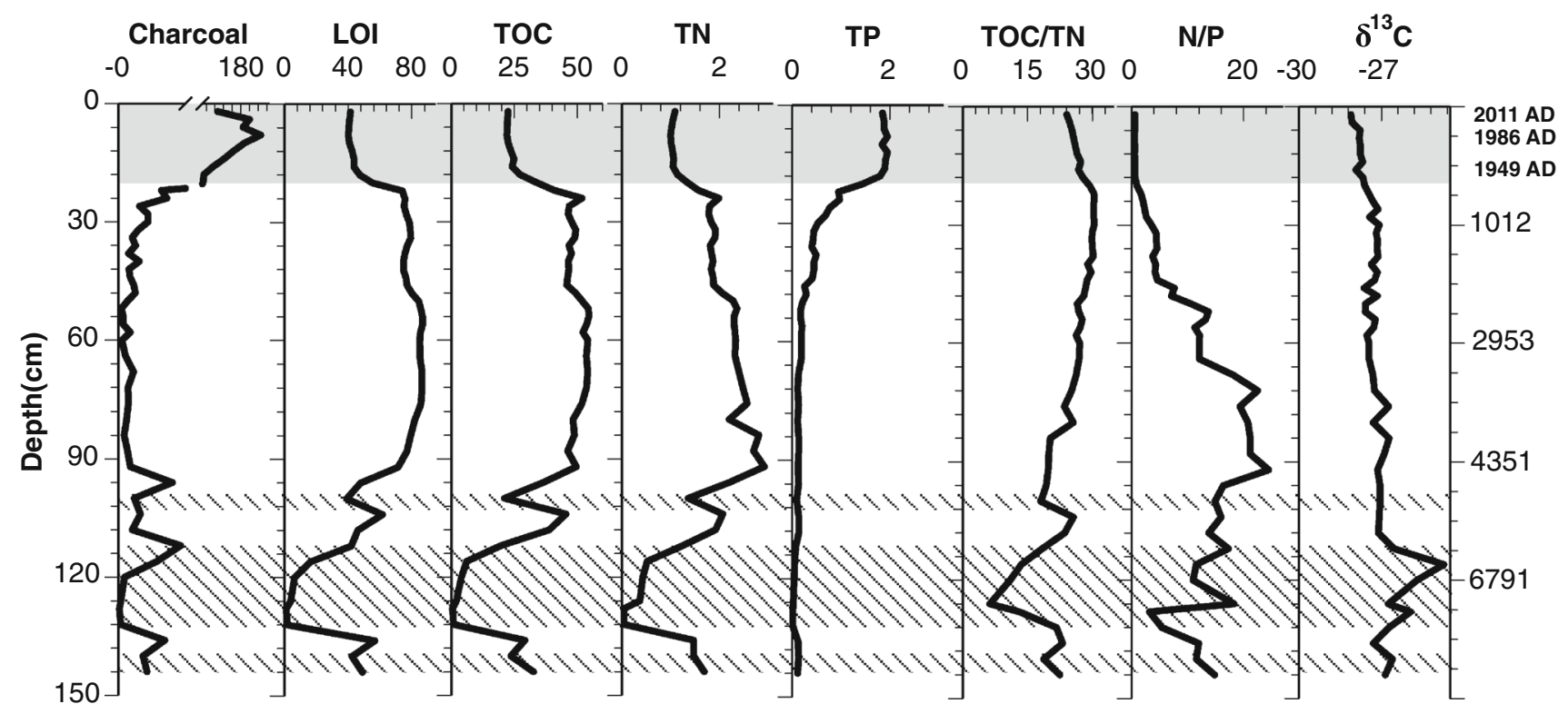

Fig. 4 Paleolimnological measurements from the sediment core collected from Ocean Pond, FL, USA. Zones were determined from K-means cluster analysis with the gray bar representing the modern Rx-fire period (Cluster 1) and striped bars representing Cluster 2 with the other areas representing Cluster 3. Dates were determined by the dating model combining the CRS excess ${ }^{210} \mathrm{~Pb}$ model and three AMS ${ }^{14} \mathrm{C}$ dates on charcoal fragments. The ${ }^{210} \mathrm{~Pb}$-derived core dates are reported in $\mathrm{AD}$ notation to match historic accounts of burning in the Osceola National Forest, and dates below are reported as years before present. Charcoal is measured as macrocharcoal $(>125 \mu \mathrm{m})$ and reported as an accumulation rate of \# $\mathrm{cm}^{-2}$ year ${ }^{-1}$ dry sediment. LOI is loss on ignition and reported as a percent. TOC and TN are total organic carbon and total nitrogen, respectively, and both are reported as percent. TP is total phosphorus and is reported as $\mathrm{mg} / \mathrm{g}$ sediment. TOC/TN is the molar ratio of $\mathrm{C}$ and $\mathrm{N}$. $\mathrm{N} / \mathrm{P}$ is the molar ratio of total nitrogen and phosphorus. $\delta^{13} \mathrm{C}$ is reported as per mil (\%o)

\section{DISCUSSION}

The macrocharcoal profile from the Ocean Pond sediment core matched the recorded dates of prescribed fire (top $18 \mathrm{~cm}$, Cluster 1, Dusenbury 1979) as well as recorded several fire events (macrocharcoal spikes) prior to European-settlement around the lake, which are attributed to Native American, colonial, or natural ignition (Whitlock et al. 2010). Macrocharcoal deposition was the highest during the Rx-fire period when compared to other depths of the core, which is likely due to prescribed burning practices increasing the frequency, proximity, and length of burn period (Ryan et al. 2013). The Rx-fire record from Ocean Pond, FL reported here demonstrates alterations to material inputs, biogeochemical processes, and nutrient stoichiometry resulting from decades of repeated prescribed burning. 


\section{Alterations to nutrient deposition and biogeochemical processes}

Modern fire events have been identified as drivers of soil properties (Shakesby and Doerr 2006), erosional dynamics (Moody et al. 2013) and nutrient inputs to stream ecosystems (Betts and Jones 2009; Coombs and Melack 2013), but much less is known of the ecological impacts on lake biogeochemistry and ecology from repeated Rx-fire. The Ocean Pond sediment core showed stratigraphic shifts in nutrient storage of $\mathrm{C}, \mathrm{N}$, and $\mathrm{P}$ with $\mathrm{C}$ and $\mathrm{N}$ decreasing and $\mathrm{P}$ increasing during the Rx-fire period (Figs. 3 and 4). The decreases in $\mathrm{C}$ and $\mathrm{N}$ deposition were also experienced during other burn periods of the lake's history while the $\mathrm{P}$ increase was unique to the Rx-fire period (Fig. 3). Acute and episodic fire events have been shown to decrease $\mathrm{C}$ and $\mathrm{N}$ in forests but the impacts of repeated Rx-fire from decades of repeated burning have not been established (Dunnette et al. 2014; Butler et al. 2017). Also, increased inputs of phosphorus into aquatic resources have been measured in burned areas when compared to unburned areas (Johnson et al. 2014; Leys et al. 2016). These trends differ from several studies where $\mathrm{C}, \mathrm{N}$, and $\mathrm{P}$ inputs collectively increased in aquatic environments following burn events when compared to unburned areas (Earl and Blinn 2003; Coombs and Melack 2013), but these studies focused on episodic events and acute samplings instead of decadal impacts. The stratigraphic shifts in nutrient deposition throughout the Rx-fire period of Ocean Pond suggest that these biogeochemical alterations could show varying trends when comparing episodic sampling to chronic impacts. Leys et al. (2016) suggested that erosional inputs from wildfires could remain for $15-30$ years post-fire. The prescribed fire management of the Osceola National Forest and many other managed forests follow a rotational practice on an annual scale, which would confound this recovery period and cause nonnatural conditions in prescribed fire-managed systems.

The decreases in $\mathrm{C}$ and $\mathrm{N}$ deposition when compared to non-fire periods are supported by several biogeochemical processes known for each nutrient. During a burning event, $\mathrm{C}$ and $\mathrm{N}$ are more likely to form volatile compounds exiting as gaseous components while $\mathrm{P}$ lacks a predominant aerosol form to its biogeochemistry (Kloss et al. 2012; Butler et al. 2017). In some wildfire areas, the volatilization of $\mathrm{C}$ and $\mathrm{N}$ has been suggested as a driver of isotopic changes related to the lighter isotope leaving the ecosystem causing isotopic signatures to be heavier (Dunnette et al. 2014). This was not the case for the Rx-fire period of Ocean Pond, FL which could be linked to Rx-fires being low in intensity (Ryan et al. 2013; Stephan et al. 2015), but the fire event around 6400 YBP did coincide with the greatest increase in $\delta^{13} \mathrm{C}$ signatures in the core. Another process capable of causing decreases of $\mathrm{C}$ and $\mathrm{N}$ deposition

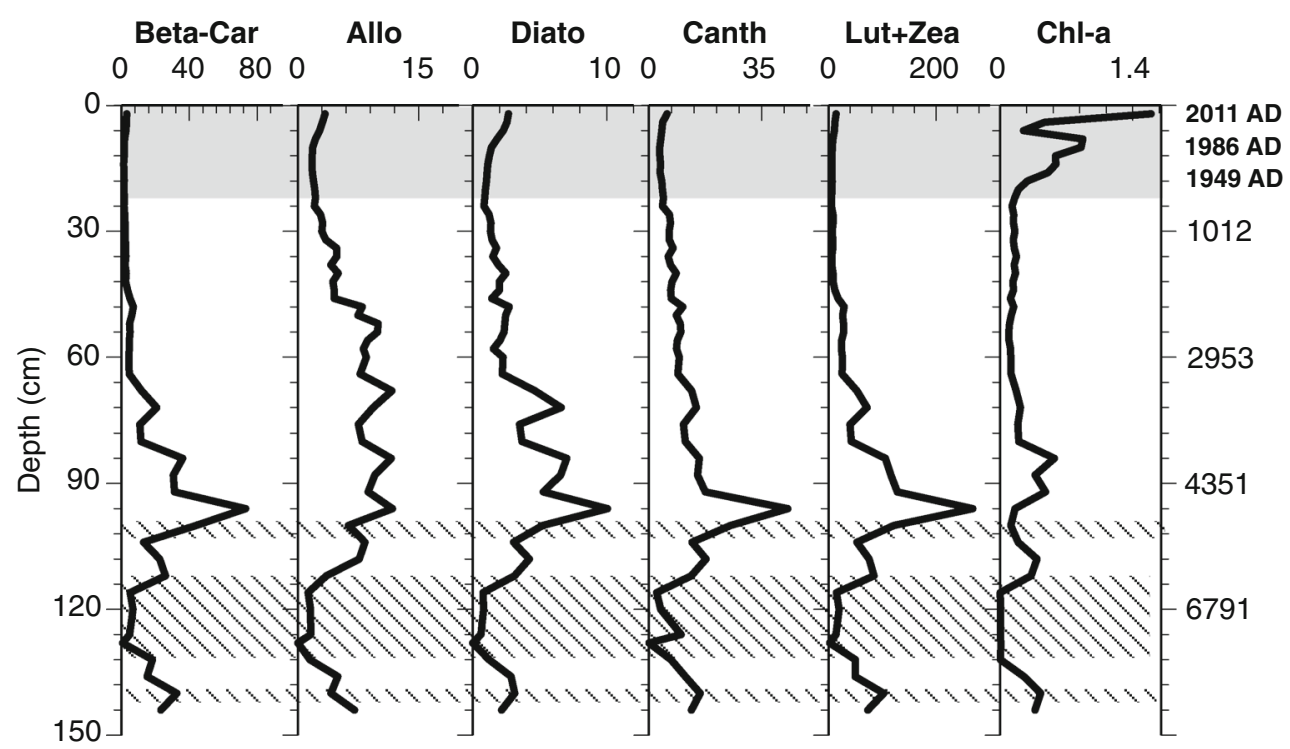

Fig. 5 Photosynthetic pigment measurements from the sediment core collected from Ocean Pond, FL, USA. Zones were determined from $\mathrm{K}$-means cluster analysis with the gray bar representing the modern Rx-fire period (Cluster 1) and striped bars representing Cluster 2 with the other areas representing Cluster 3. Dates were determined by the dating model combining the CRS excess ${ }^{210} \mathrm{~Pb}$ model and three $\mathrm{AMS}{ }^{14} \mathrm{C}$ dates on charcoal fragments. The ${ }^{210} \mathrm{~Pb}$-derived core dates are reported in AD notation to match historic accounts of burning in the Osceola National Forest, and dates below are reported as years before present. All pigments are reported as nmol pigment $\mathrm{g}^{-1}$ organic matter. Primary producer associations for each pigment are Beta-Carotene (total abundance), Alloxanthin (cryptophytes), Diatoxanthin (diatoms), Canthaxanthin (cyanobacteria), Lutein + Zeaxanthin (chlorophytes + cyanobacteria), Chlorophyll-a (total abundance, degradation) (Leavitt and Hodgson 2001) 


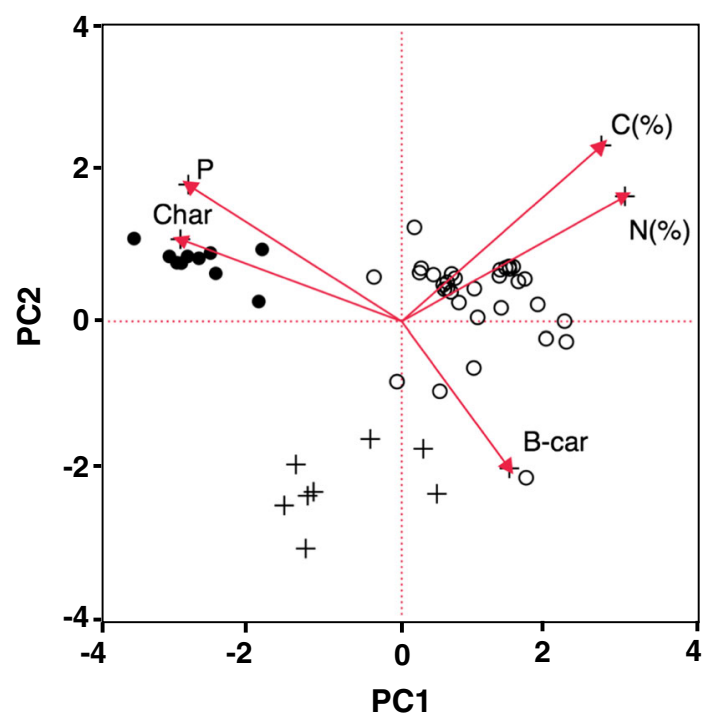

Fig. 6 Scatterplot of principal components 1 (PC1) and 2 (PC2) showing ordinations of macrocharcoal, nutrients, and beta-carotene. $\mathrm{PC} 1$ and $\mathrm{PC} 2$ represent $54.8 \%$ and $26.1 \%$ of the variance of the dataset, respectively. Plot symbols correspond to the k-means cluster analysis with closed circles (filled circle) for cluster 1, plus $(+)$ for cluster 2, and open circles (open circle) for cluster 3

during burned periods could be related to increased terrestrial vegetation growth resulting in more $\mathrm{C}$ and $\mathrm{N}$ remaining on the landscape in biomass rather than entering the lake. While burning can increase forest-N stocks from regrowth over long timescales (i.e. millennial) (Kloss et al. 2012), on the shorter, decadal, timescales of Rx-fire use, $\mathrm{N}$ accumulation was shown to decrease (Giesen et al. 2008). Likewise, a recent study on Australian forest soils showed decreases in labile forms of $\mathrm{C}$ and $\mathrm{N}$ as well as increases in $P$ following burn events (Butler et al. 2017). Regardless of the mechanism, the decrease of $\mathrm{C}$ and $\mathrm{N}$ deposition during the Rx-fire period of Ocean Pond links the management of burning forests with a sustained decrease in $\mathrm{C}$ and $\mathrm{N}$ storage over decades.

The increased $\mathrm{P}$ deposition during the Rx-fire period was a substantial increase from multiple historic periods preceding the modern burn period (Fig. 3). The increase in P storage ( $>200 \%$ ) also caused dramatic decreases in N/P ratios (Fig. 3). Phosphorus has been shown to be a primary constituent of eroded materials from burned areas into aquatic environments (Earl and Blinn 2003; Wanthongchai et al. 2008; Coombs and Melack 2013; Leys et al. 2016), but these inferences were from episodic fires and generally included inputs of $\mathrm{N}$ as well. The N/P ratios recorded during the Rx-fire period from Ocean Pond show a novel development in the lake's N/P deposition (Figs. 3, 4). Although sediment N/P does not necessarily reflect historic water column N/P, changes in N/P deposition shown in the Ocean Pond sediment core, suggest an alteration to the lake's biogeochemistry linked to chronic prescribed burning. The dramatic changes to $\mathrm{N}$ and $\mathrm{P}$ deposition in Ocean Pond during the period of modern Rx-fire could support changes seen in other studies focusing on $\mathrm{N}$ removal in lakes (Finlay et al. 2013), N/P decreases in global lake sediments (Yan et al. 2016) and increased $P$ accumulation in reservoirs (Maavara et al. 2015). In each of these studies, large changes in $\mathrm{N}$ and $\mathrm{P}$ dynamics were documented, but fire impacts were not considered as a potential primary or secondary driver of nutrient stoichiometry.

Biogeochemical alterations from fire events can impact nutrient runoff (Wanthongchai et al. 2008; Coombs and Melack 2013), carbon dynamics (Cotrufo et al. 2016) and sediment delivery (Moody et al. 2013). Whereas most of these impacts have been investigated on episodic wildfire events, the sediment record from Ocean Pond, FL documents a chronic period of prescribed fire management over decadal timescales and links Rx-fire with changes in nutrient deposition in the system. Carbon storage in lake systems has been shown to increase during modern periods in temperate (Heathcote and Downing 2012), boreal (Heathcote et al. 2015), and tropical systems (Sanders et al. 2017) labeling lake sediments as a sink for carbon. The decreases in $\mathrm{C}$ deposition from the Ocean Pond, FL core suggest that long-term Rx-fire could offset some of the storage capacity attributed to lake sediments in global carbon models. Likewise, in 2016, over 83000 fires covering over $16187 \mathrm{~km}^{2}$ were used in forest management in the USA alone (www.nifc.gov). By applying the stratigraphic changes recorded in Ocean Pond, FL, the impacts of widespread Rx-fire need to be considered as a driver of nutrient dynamics in lake and other aquatic ecosystems.

\section{Prescribed fire impacts on lake processes}

The beta-carotene record from Ocean Pond (Fig. 5) shows that primary producer abundance increased during historic periods of fire ( $\sim 4500 \mathrm{YBP}$ and bottom of core) but was low during the modern Rx-fire period. Beta-carotene is a proxy for total primary producer abundance and has been shown in other paleolimnological investigations to be more useful than chlorophyll-a due to the labile nature of chlorophyll-a (Leavitt and Hodgson 2001; Waters et al. 2015). As a result, the increases in chlorophyll-a in the top of the Ocean Pond core are inferred as degradation differences as well as some terrestrial vegetation material entering the lake, since all aquatic primary producer markers were low during the Rx-fire period (Fig. 5). Aquatic primary producers in wildfire studies looking at single events and small temporal periods (1 month) have largely been unaffected (Earl and Blinn 2003). Other studies support the Ocean Pond Rx-fire period with the decreased abundance of primary producers in burned areas 
(Harris et al. 2015). However, our study is unique on the temporal scale (decades) and ecosystem measured (lake verses stream). In addition, two historic periods of fire show increases in primary producer abundance (Fig. 5). Two primary mechanisms could be influencing these differences in total abundance between the fire periods. First, fire impacts on eroded materials could differ between repeated Rx-fires and other fire events. Compared with modern Rx-fires, most historic fires generally burn with greater intensity and area (Elliot and Vose 2006). Looking at sediment deposits, Oldfield and Crowther (2007) demonstrated that differences in fire intensity alter soil properties eroding into lake systems, which are capable of impacting nutrient availability and biogeochemical cycles. Second, the repeated burning of the landscape surrounding Ocean Pond, FL could have impacted the aquatic environment so that primary productivity is limited by factors other than nutrient inputs. Fire events have been shown to increase dissolved organic carbon (Brown et al. 2015) and turbidity (Reale et al. 2015) in stream ecosystems. Increases in both of these water-quality parameters could limit light in the photic zone thus limiting phytoplankton growth.

Photosynthetic pigments also showed changes in primary producer community structure during historic periods of fire as well as the low abundance during the Rx-fire period (Fig. 5). Most phytoplankton groups increased during the pre-modern fire events in the bottom of the core and the $\sim 4500$ YPB event. Diatoms (diatoxanthin), cyanobacteria (canthaxanthin), and chlorophytes + cyanobacteria (lutein + zeaxanthin) all peaked during the 4500 YBP fire period. Cryptophytes (alloxanthin) increased during these fire periods and maintained elevated abundance following the 4500 YPB fire. Cryptophytes are motile phytoplankton and have been shown to outcompete other planktors during high turbidity periods in other subtropical systems (Waters et al. 2010). While the increased abundances during the historic fire periods demonstrate the potential for fire-eroded materials to impact aquatic primary producers, the period of modern Rx-fire showed very little change in all phytoplankton groups with slight increases in the top samples for some phytoplankton groups. While phosphorus inputs have increased during the period of modern prescribed burning, phytoplankton growth has been limited most likely from the increased dissolved organic carbon or turbidity. Ocean Pond is currently an acidic system with high dissolved organic carbon (Binford and Brenner 1986), which most likely limited growth during the modern period as well as supported the increased cryptophytes in the system following the 4500 YPB fire period. Whether or not similar limnological conditions develop in other lakes receiving large amounts of burned materials still remains to be determined.

\section{Management implications}

The application of prescribed fires greatly reduces wildfire events by removing excess fuel from the forested ecosystem as well as simulating "natural" fire regimes (Ryan et al. 2013). The questioning of prescribed fire as an emulation of historic fire events has been considered previously but focused on the more terrestrial impacts of $\mathrm{Rx}$ fire such as intensity, season of burning, and unburned refugia (Ryan et al. 2013). When considering adjacent aquatic environments to Rx-fire areas, the dramatic changes to $\mathrm{C}, \mathrm{N}$, and $\mathrm{P}$ deposition in Ocean Pond, FL suggest that chronic prescribed burning could be a driver of material inputs into aquatic ecosystems and a potential cause of aquatic ecological change. With regards to nutrient increases $(\mathrm{P})$ and decreases $(\mathrm{C}$ and $\mathrm{N})$, forest managers should partner with aquatic ecosystem mangers to better understand the biogeochemical and ecological impacts repeated prescribed burning could cause. While Ocean Pond, FL did not experience a dramatic change in the primary producer community during the burn period, the alterations to nutrient inputs and stoichiometry resulting from Rx-fire management did cause a novel period of nutrient dynamics for the lake. A second management consideration resulting from our study, is the temporal application of Rx-fire rotations. The repeated burning over decades appeared to magnify biogeochemical changes as well as fail to follow suggested recovery periods from wildfire sediment records (Leys et al. 2016). While few aquatic monitoring programs extend throughout multiple decades, the sediment record of Ocean Pond, FL allowed the investigation of chronic impacts rather than episodic burn sampling. The decadal scale impacts of prescribed burning should be a future consideration in other terrestrial ecosystems where Rx-fire is a repeated and primary constituent of the management.

Acknowledgements Funding for this research was provided by Valdosta State University through a Faculty Research Seed Grant and by Auburn University with funds provided to MNW. Ted West, James Ragan, Sean Earley, and Ben Webster aided in fieldwork and lab analysis. Christopher Lydick supplied important information of prescribed fire in the Osceola National Forest. Ben Webster constructed Fig. 1. We are very grateful to two anonymous reviewers whose comments greatly improved the manuscript.

\section{REFERENCES}

Appleby, P.G., and F. Oldfield. 1983. The assessment of ${ }^{210} \mathrm{~Pb}$ data from sites with varying sediment accumulation rates. Hydrobiologia 103: 29-35. 
Battle, J., and S.W. Golladay. 2003. Prescribed fire's impact on water quality of depressional wetlands in southwestern Georgia. American Midland Naturalist 150: 15-25.

Betts, E.F., and J.B.J. Jones. 2009. Impact of wildfire on stream nutrient chemistry and ecosystem metabolism in boreal forest catchments of interior Alaska. Arctic, Antarctic, and Alpine Research 41: 407-417.

Binford, M.W., and M. Brenner. 1986. Dilution of ${ }^{210} \mathrm{~Pb}$ by organic sedimentation in lakes of different trophic states, and application to studies of sediment-water interactions. Limnology and Oceanography 31: 584-595.

Bodi, M.B., D.A. Martin, V.N. Balfour, C. Santin, S.H. Doerr, P. Pereira, A. Cerda, and J. Mataix-Solera. 2014. Wild land fire ash: Production, composition and eco-hydro-geomorphic effects. Earth-Science Reviews 130: 103-127.

Brenner, M., and M.W. Binford. 1988. Relationships between concentrations of sedimentary variables and trophic state in Florida lakes. Canadian Journal of Fisheries and Aquatic Sciences 45: 294-300.

Brenner, M., T.J. Whitmore, J.H. Curtis, D.A. Hodell, and C.L. Schelske. 1999. Stable isotopes $\left(\delta^{13} \mathrm{C}\right.$ and $\left.\delta^{15} \mathrm{~N}\right)$ of sedimented organic matter as indicators of historic lake trophic state. Journal of Paleolimnology 22: 205-221.

Brown, L.E., J. Holden, S.M. Palmer, K. Johnston, S.J. Ramchunder, and R. Grayson. 2015. Effects of fire on the hydrology, biogeochemistry, and ecology of peatland river systems. Freshwater Science 34: 1406-1425.

Butler, O.M., T. Lewis, and C. Chen. 2017. Fire alters soil labile stoichiometry and litter nutrients in Australian eucalypt forests. International Journal of Wildland Fire 26: 783-788.

Coombs, J.S., and J.M. Melack. 2013. Initial impacts of a wildfire on hydrology and suspended sediment and nutrient export in California chaparral watersheds. Hydrological Processes 27: 3842-3851.

Cotrufo, M.F., C.M. Boot, S. Kampf, P.A. Neslon, D.J. Brogan, T. Covino, M.L. Haddix, L.H. MacDonald, et al. 2016. Redistribution of pyrogenic carbon from hillslopes to stream corridors following a large montane wildfire. Global Biogeochemical Cycles 30: 1348-1355.

Dunnette, P.V., P.E. Higuera, K.K. McLauchlan, K.M. Derr, C.E. Briles, and M.H. Keefe. 2014. Biogeochemical impacts of wildfires over four millennia in a Rocky Mountain subalpine watershed. New Phytologist 203: 900-912.

Dusenbury, R.B. 1979. A history of the Osceola National Forest. United States National Forest Service. Publication: OSCF00310.

Earl, S.R., and D.W. Blinn. 2003. Effects of wildfire ash on water chemistry and biota in the south-western U.S.A. streams. Freshwater Biology 48: 1015-1030.

Elliot, K.J., and J.M. Vose. 2006. Fire effects on water quality: A synthesis of response regulating factors among contrasting ecosystems. Second Interagency Conference on Research in Watersheds, USDA SRS Coweeta Hydrologic Laboratory, p. 12.

Finlay, J.C., G.E. Small, and R.W. Sterner. 2013. Human influences on nitrogen removal in lakes. Science 342: 247-250.

Giesen, T.W., S.S. Perakis, and K. Cromack. 2008. Four centuries of soil carbon and nitrogen change after stand-replacing fire in a forest landscape in the western Cascade Range of Oregon. Canadian Journal of Forest Research 38: 2455-2464.

Harris, H.E., C.V. Baxter, and J.M. Davis. 2015. Debris flows amplify effects of wildfire on magnitude and composition of tributary subsidies to mainstem habitats. Freshwater Science 34: 1457-1467.

Haliuc, A., S.M. Hutchinson, G. Florecu, and A. Feurdean. 2016. The role of fire in landscape dynamics: An example of two sediment records from the Rodna Mountains, northern Romanian Carpathians. CATENA 137: 432-440.
Heathcote, A.J., and J.A. Downing. 2012. Impacts of eutrophication on carbon burial in freshwater lakes in an intensively agricultural landscape. Ecosystems 15: 60-70.

Heathcote, A.J., N.J. Anderson, Y.T. Prairie, D.R. Engstrom, and P.A. del Giorgio. 2015. Large increases in carbon burial in northern lakes during the Anthropocene. Nature Communications. https:// doi.org/10.1038/ncomms10016.

Hudiburg, T.W., P.E. Higuera, and J.A. Hicke. 2017. Fire-regime variability impacts forest carbon dynamics for centuries to millennia. Biogeosciences 14: 3873-3882.

Johnson, D.W., R.F. Walker, D.W. Glass, C.M. Stein, J.B. Murphy, R.R. Blank, and W.W. Miller. 2014. Effects of thinning, residue mastication, and prescribed fire on soil and nutrient budgets in a Sierra Nevada mixed-conifer forest. Forest Science 60: 170-179.

Kloss, S., O. Sass, C. Geitner, and J. Prietzel. 2012. Soil properties and charcoal dynamics of burnt soils in the Tyrolean Limestone Alps. CATENA 99: 75-82.

Leavitt, P.R., and D.A. Hodgson. 2001. Sedimentary pigments. In Tracking environmental change using lake sediments, terrestrial, algal, and siliceous indicators, vol. 3, ed. J.P. Smol and H.J.P. Birks, 295-325. Dordrecht: W.M.Last. Kluwer.

Leys, B., P.E. Higuera, K.K. McLauchlan, and P.V. Dunnette. 2016. Wildfires and geochemical change in a subalpine forest over the past six millennia. Environmental Research Letters 11: 125003.

Maavara, T., C.T. Parsons, C. Ridenour, S. Stojanovic, H.H. Durr, H.R. Powley, and P.V. Cappellen. 2015. Global phosphorus retention by river damming. Proceedings of the National Academy of Sciences 112: 15603-15608.

Meyers, P.A., and J.L. Teranes. 2001. Sediment organic matter. In Tracing environmental changes using lake sediments, ed. W.M. Last and J.P. Smol, 239-269. Dordrecht: Kluwer Academic Publishers.

Mohr, J.A., C. Whitlock, and C.N. Skinner. 2000. Postglacial vegetation and fire history, eastern Klamath Mountains, California, USA. The Holocene 10: 587-601.

Moody, J.A., R.A. Shakesby, P.R. Robichaud, S.H. Cannon, and D.A. Martin. 2013. Current research issues related to post-wildfire runoff and erosion processes. Earth-Science Reviews 122: $10-37$.

Oldfield, F., and J. Crowther. 2007. Establishing fire incidence in temperate soils using magnetic measurements. Palaeogeography, Palaeoclimatology, and Palaeoecology 249: 362-369.

Paerl, H.W., N.S. Hal, and E.S. Calandrino. 2011. Controlling harmful cyanobacterial blooms in a world experiencing anthropogenic and climatic-induced change. Science of the Total Environment 409: 1739-1745.

Parlak, A.O., M. Parlak, H. Blanco-Canqui, W.H. Schacht, J.A. Guretzky, and M. Mamo. 2015. Patch burning: Implications on water erosion and soil properties. Journal of Environmental Quality 44: 903-909.

Reale, J.K., D.J. Van Horn, K.E. Condon, and C.N. Dahm. 2015. The effects of catastrophic wildfire on water quality along a river continuum. Freshwater Science 34: 1426-1442.

Ryan, K.C., E.E. Knapp, and J.M. Varner. 2013. Prescribed fire in North American forests and woodlands: History, current practice, and challenges. Frontiers in Ecology. https://doi.org/10. $1890 / 120329$.

Sanders, L.M., K.H. Taffs, D.J. Stokes, C.J. Sanders, J.M. Smoak, A. Enrich-Prast, P.A. Macklin, I.R. Santos, and H. Marotta. 2017. Carbon accumulation in Amazonian floodplain lake: A significant component of Amazon budgets? Limnology and Oceanography Letters 2: 29-35.

Schelske, C.L., E.F. Lowe, L.E. Battoe, M. Brenner, M.F. Coveney, and W.F. Kenney. 2005. Abrupt biological response to hydrologic and land-use changes in Lake Apopka, Florida, USA. 
Ambio 34: 192-198. https://doi.org/10.1579/0044-7447-34.3. 192.

Shakesby, R.A., and S.H. Doerr. 2006. Wildfire as a hydrological and geomorphological agent. Earth-Science Reviews 74: 269-307.

Smithwick, E.A.H., M.G. Turner, M.C. Mack, and F.S. Chapin III. 2005. Postfire soil N cycling in northern conifer forests affected by severe, stand-replacing wildfires. Ecosystems 8: 163-181.

Smol, J.P. 2008. Pollution of lakes and rivers: A paleoenvironmental perspective, 2nd ed, 383. Oxford.: Blackwell Publishing.

Stephan, K., K.L. Kavanagh, and A. Koyama. 2015. Comparing the influence of wildfire and prescribed burns on watershed nitrogen biogeochemistry using N-15 natural abundance in terrestrial and aquatic ecosystem components. PLoS ONE. https://doi.org/10. 1371/journal.pone.0119560.

Stephens, S.L., T. Meixner, M. Poth, B. McGurk, and D. Payne. 2004. Prescribed fire, soils, and stream water chemistry in a watershed in the Lake Tahoe Basin, California. International Journal of Wildland Fire 13: 27-35.

Stuiver, M., P.J. Reimer, and R.W. Reimer. 2018. CALIB 7.1. http:// calib.org.

Vose, J.M., W.T. Swank, B.D. Clinton, J.D. Knoepp, and L.M. Swift Jr. 1999. Using stand replacement fires to restore southern Appalachian pine-hardwood ecosystems: Effects on mass, carbon, and nutrient pools. Forest Ecological Management 114: $215-226$.

Wanthongchai, K., J. Bauhus, and J.G. Goldammer. 2008. Nutrient losses through prescribed burning aboveground litter and understory in dry dipterocarp forests of different fire history. CATENA 74: 321-332.

Waters, M.N., M.F. Piehler, J.M. Smoak, and C.S. Martens. 2010. The development and persistence of alternative ecosystem states in a large, shallow lake. Freshwater Biology 55: 1249-1261.

Waters, M.N., C.L. Schelske, and M. Brenner. 2015. Cyanobacterial dynamics in shallow Lake Apopka (Florida, USA) before and after the shift from a macrodominated to a phytoplanktondominated state. Freshwater Biology 60: 1571-1580.

Whitlock, C., and C. Larsen. 2001. Charcoal as a fire proxy. In Tracking environmental change using lake sediments, terrestrial, algal, and siliceous indicators, vol. 3, ed. J.P. Smol and H.J.P. Birks, 75-97. Dordrecht: W.M.Last. Kluwer.

Whitlock, C., P.E. Higuera, D.B. McWethy, and C.E. Briles. 2010. Paleoecological perspectives on fire ecology: Revisiting the fireregime concept. The Open Journal of Ecology 3: 6-23.
Yan, Z., W. Han, J. Penuelas, J. Sardans, J.J. Elser, E. Du, P.B. Reich, and J. Fang. 2016. Phosphorus accumulates faster than nitrogen globally in freshwater ecosystems under anthropogenic impacts. Ecology Letters. https://doi.org/10.1111/ele.12658.

\section{AUTHOR BIOGRAPHIES}

Matthew N. Waters $(\square)$ is an Assistant Professor of environmental science at the Auburn University. His research interests include using the sediment record of lakes to link landscape processes with autochthonous responses. He focuses primarily on subtropical and tropical lake systems and reconstructs environmental change throughout the Holocene.

Address: Crop, Soil and Environmental Sciences Department, Auburn University, 201 Funchess Hall, Auburn, AL 36849, USA.

e-mail: mwaters@auburn.edu

Alexander P. Metz is a graduate student of the Auburn University attached to the Department of Crop, Soil and Environmental Sciences. His research interests include human activities on lake and coastal bays as well as spatial statistics and GIS.

Address: Crop, Soil and Environmental Sciences Department, Auburn University, 201 Funchess Hall, Auburn, AL 36849, USA.

e-mail: apm0032@tigermail.auburn.edu

Joseph M. Smoak is a Professor of biogeochemistry and radiochemistry at the University of South Florida, St. Petersburg. His research interests include carbon sequestration in marine and wetland environments, human impacts on coastal systems, and sedimentation changes throughout the Anthropocene.

Address: Environmental Science University of South Florida, St. Petersburg, FL, USA.

e-mail:smoak@mail.usf.edu

Hunter Turner is a graduate, holding a degree in Biology from the Valdosta State University. His research interests include human and environmental impacts on biological organisms along the eastern seaboard of the USA.

Address: Biology Department, Valdosta State University, Valdosta, GA 31698, USA.

e-mail: hunterturner19@hotmail.com 